\title{
Analysis of Properties of Microfita Antenna with Altered Ground Plane
}

\author{
OTÁVIO PAULINO LAVOR \\ Federal Rural University of Semiarid \\ Pau dos Ferros, BRAZIL
}

\begin{abstract}
This work analyzes the influence of a modified ground plane on a microfiche antenna with a circular patch on a rectangular substrate. The considered modification is the connection of a rectangular border to a central circle. When considering the change, better bandwidth is achieved leading to an increase of $122 \%$. The prototype is built so that measured and simulated data can be compared.
\end{abstract}

Keywords: Communications, Wireless Communications, Planar antenna, Rectangular Substrate, Bandwidth.

Received: June 10, 2020. Revised: November 21, 2020. Accepted: December 11, 2020. Published: December 24, 2020.

\section{Introduction}

Antennas are devices that radiate or receive radio waves [1] and play an important role in communication systems. The performance of these devices influences the efficiency of the systems of which they are part, and to describe this performance it is necessary to analyze several parameters. The parameters to be analyzed depend on the application and may show a radiation pattern, directivity, gain and bandwidth.

Among the various types of antennas, one of the most used types, due to their characteristics for application in modern communication systems are microwaveable antennas [2]. These antennas are made up of a dielectric substrate that has a ground plane on its bottom and a patch on its top. As an advantage, these antennas stand out for the ease of molding flat and non-flat surfaces, simple construction, low cost, versatility in terms of resonance frequency pattern, impedance and radiation. As a disadvantage, we can mention the low efficiency, directivity, as well as the bandwidth of a few percent [3].

The antenna patch can have several geometric shapes and one of the geometric shapes that we can mention is the circular patch. A disk microfiche antenna has been proposed using an arrangement of conductive pathways connecting the patch to the modified ground plane with curved branches [4]. This antenna is designed to cover the $2.4 \mathrm{GHz}$ band and a better bandwidth has been achieved. Changes were made to the ground plane using a broken ring resonator to improve the bandwidth [5]. The broken ring resonator was also used inside a circular opening in the ground plane to create band rejection in a UWB planar antenna [6].

The metamaterial has been applied to improve the gain of a circular microfiche antenna developed for the detection of partial discharges and an increase of $1.15 \mathrm{~dB}$ in the average gain of the reference antenna has been verified [7]. Circular geometry was also used in array for the project of aplication in Wireless Sensor Network (WSN), and it was found that the circular patch antenna produces more gain and less return loss compared to rectangular antenna [8].

Patch changes can be seen in a unique patch design by small modifications of the combined semicircular and triangular structures and the properties were verified through computer simulations [9]. The integration of symmetric 
circular clusters of shorting pins (CCSP) in circular microstrip patch antenna resulted in a relative suppression in XP levels of around $51 \mathrm{~dB}$ at the boresight and an average of $30 \mathrm{~dB}$ around $\pm 60^{\circ}$ on either side of the boresight in both the principal radiation planes [10]. The design and impedance analysis of a reactive Impedance surface (RIS) is made using a periodic arrangement of circular patches, which leads to a miniaturization of $55.03 \%$ [11].

As you can see, circular geometry is well used and several modifications to the antennas are considered by several authors. In order to enrich the literature in this study, this work proposes to analyze the behavior of a change in the ground plane of an antenna with a circular patch on a rectangular substrate. The modification is made considering a central circle the same size as the patch and an edge with width equal to the feed line. The circle and the border are connected by lines. The next section shows the design of the antenna.

\section{Design of the Antenna}

For a standard antenna, an antenna with a circular patch of radius $\mathrm{r}=3.7 \mathrm{~mm}$ was proposed, obtained from the cavity method [3] using equation 1 .

$$
r=\frac{F}{\left[1+\frac{2 h}{\pi \varepsilon_{T} F}\left[\ln \left(\frac{\pi F}{2 h}\right)+1,7726\right]\right]^{1 / 2}}
$$

where $\mathrm{h}$ is the thickness of the substrate, $\mathrm{er}$ is the relative permittivity and

$$
F=\frac{2,791 \cdot 10^{9}}{f_{r} \sqrt{\varepsilon_{v}}}
$$

being fr the operating frequency.

Feeding is by a microfiber line of length $b=3.68$ $\mathrm{mm}$ and a width $\mathrm{w}=1 \mathrm{~mm}$. The substrate used is of the square type, and the material used is fiberglass (FR4) with relative permittivity (cr) of 4.4 and thickness of $1.52 \mathrm{~mm}$.

A change in the ground plane is proposed in order to obtain an increase in the bandwidth of this antenna. This modification is made considering a central circle the same size as the patch and an edge with the same width as the feed line. The circle and the border are connected by lines with the same thickness as the feed line. Fig. 1 below shows the geometry of the antenna.

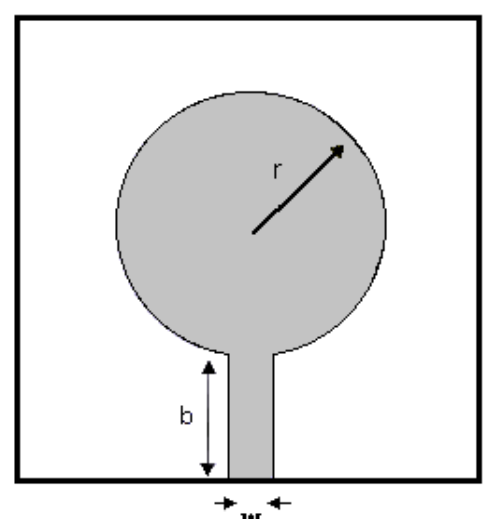

Fig. 1. Geometry of the patch of the proposed antenna.

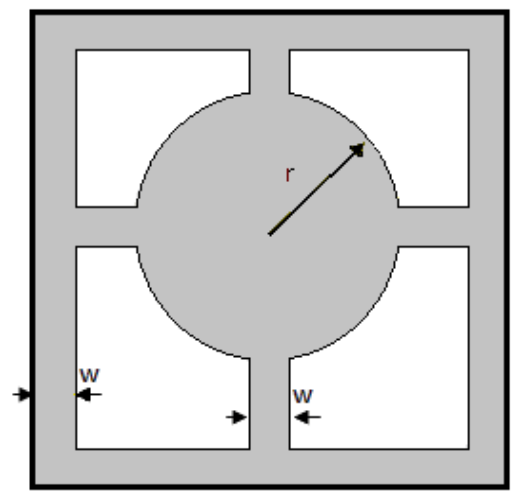

Fig. 2. Geometry of the ground plane of the proposed antenna.

The results of the simulations and the measured results of the prototypes built are described in the following section.

\section{Results}

For the standard antenna and for the proposed configuration for the ground plane described in the previous section, simulations were performed to obtain values of return loss and bandwidth. Fig. 2 shows the return loss curves as a function of the resonance frequency. 


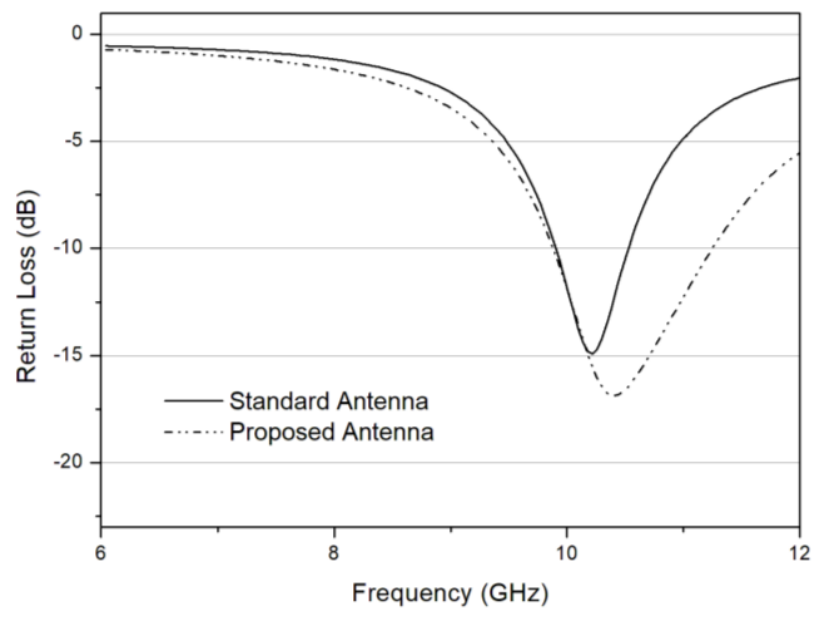

Fig. 3. Simulated return loss values (S11) as a function of the operating frequency for standard and proposed antenna.

The standard antenna has a return loss of $-14.9 \mathrm{~dB}$ with a resonance frequency of $10.22 \mathrm{GHz}$. The proposed antenna has a return loss of $-17.42 \mathrm{~dB}$ with a resonance frequency of $10.36 \mathrm{GHz}$. bandwidth of the standard antenna is $643 \mathrm{MHz}$ or $6.29 \%$, while the proposed antenna has a bandwidth of $1430 \mathrm{MHz}$ or $13.8 \%$, showing a large increase.

In relation to the radiation diagrams, Fig. 3 shows the 2D diagram and Fig. 4 shows the 3D diagram of the standard antenna. Fig. 5 shows the 2D diagram and Fig. 6 shows the 3D diagram of the proposed antenna.

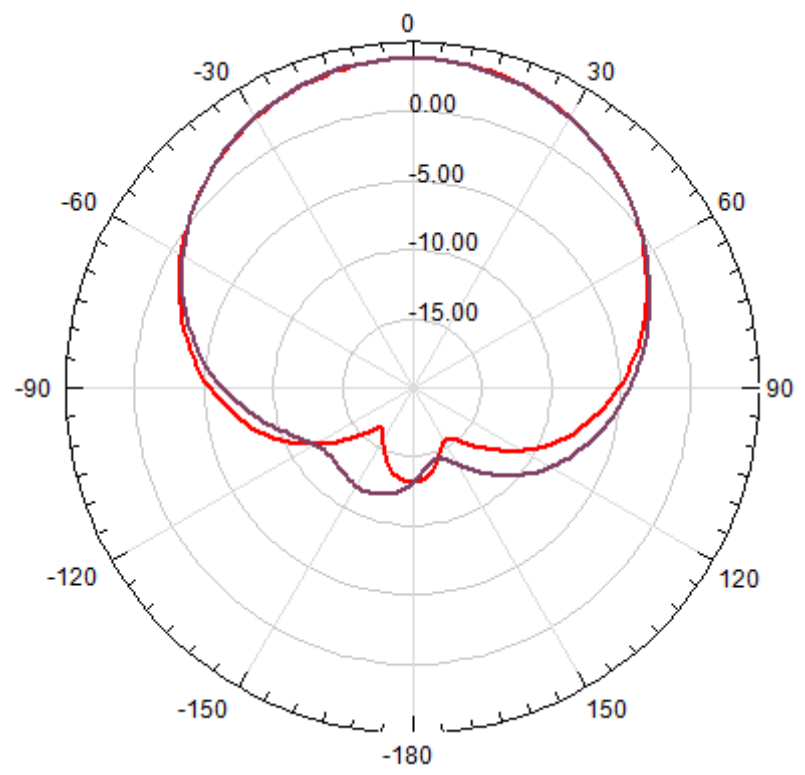

Fig. 3. 2D diagram of the standard antenna.

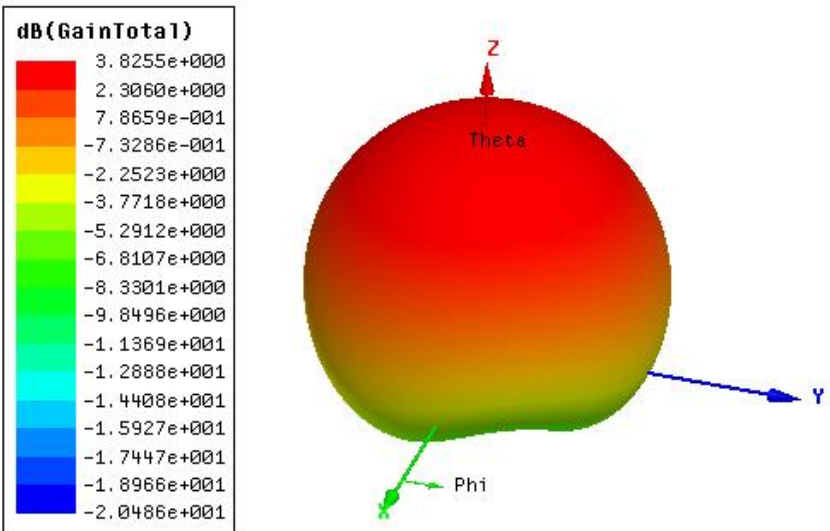

Fig. 4. 3D diagram of the standard antenna.

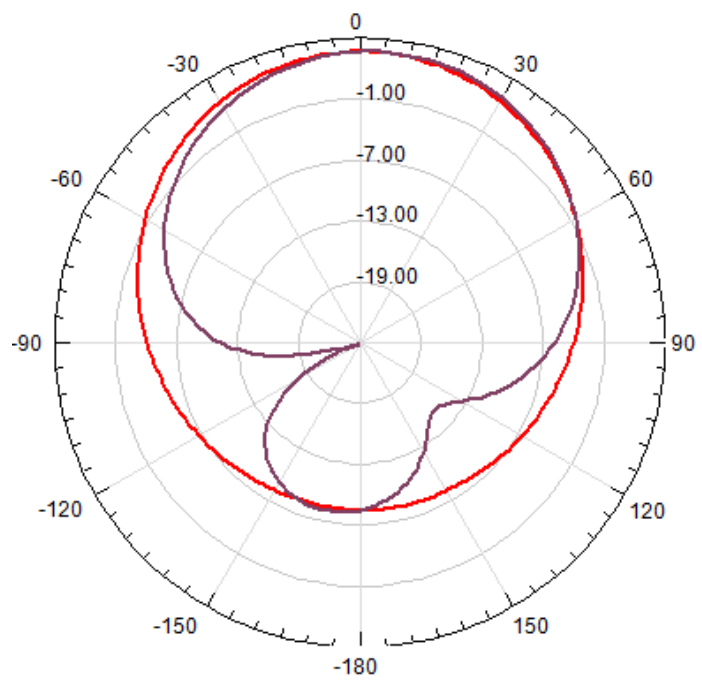

Fig. 5. 2D diagram of the proposed antenna.

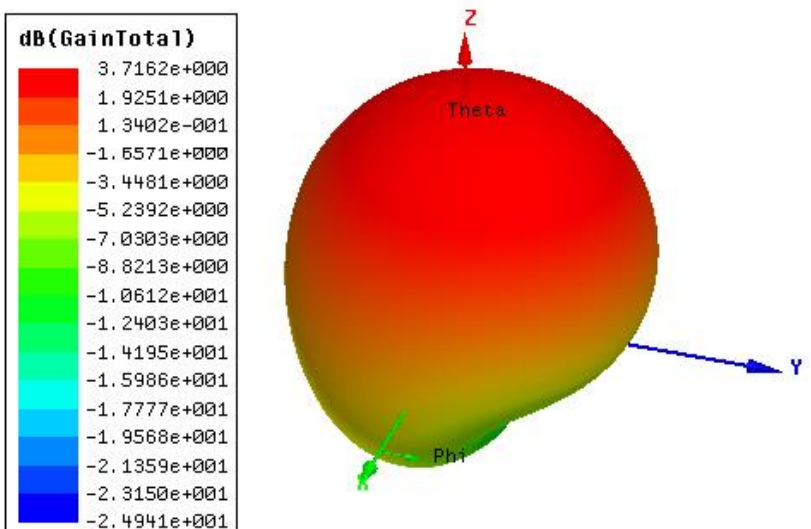

Fig. 6. 3D diagram of the proposed antenna.

As you can see, the standard antenna has a gain of $3.8255 \mathrm{~dB}$ and the proposed antenna $3.7162 \mathrm{~dB}$, 
which shows a small loss due to cuts in the ground plane.

Fig. 7 and 8 show the current distribution in the patch and ground plane of the standard antenna. Figures 9 and 10 show the current distribution of the proposed antenna.

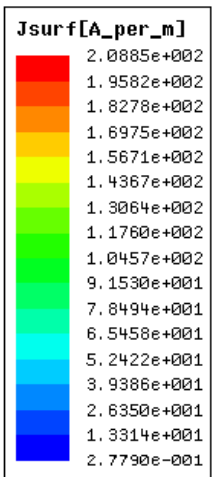

Fig. 7. Current distribution in the patch of the standard antenna.

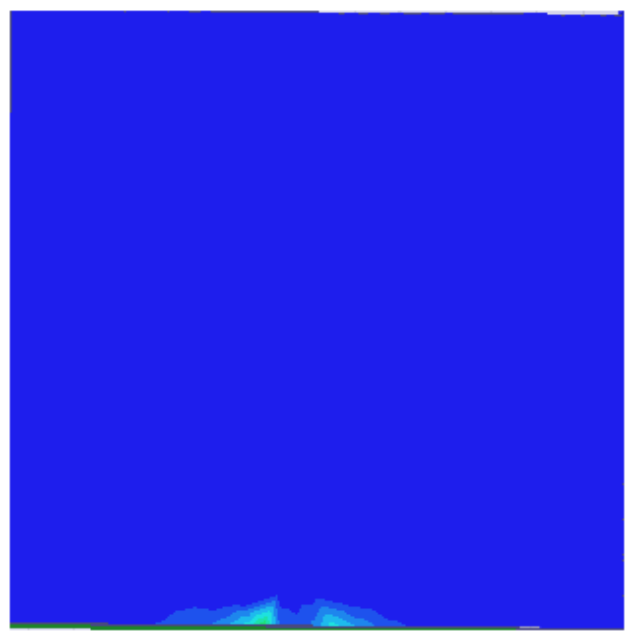

Fig. 8. Current distribution on the ground plane of the standard antenna.
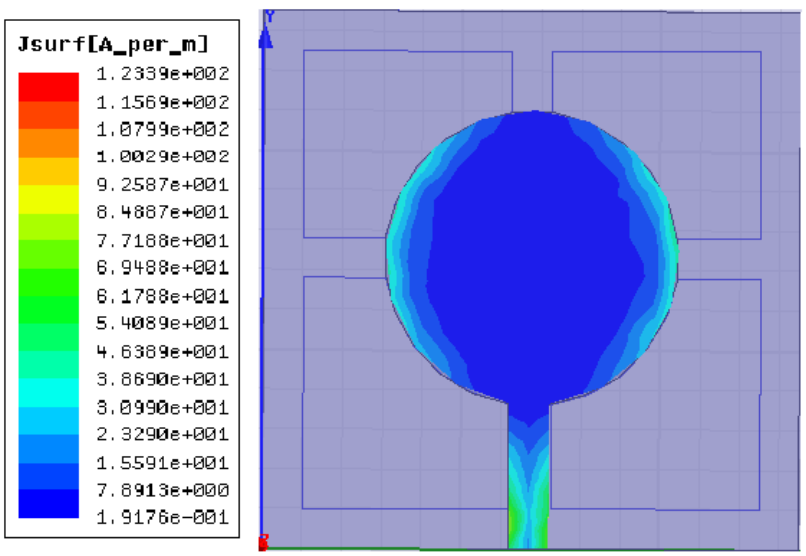

Fig. 9. Current distribution in the patch of the proposed antenna.

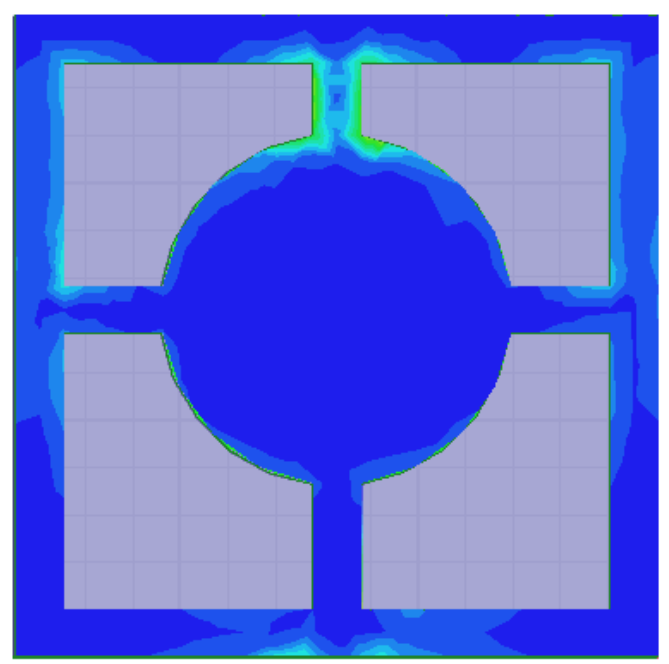

Fig. 10. Current distribution on the ground plane of the proposed antenna.

In the standard antenna, the currents are concentrated in the supply line and in the edges of the patch, as well as in the ground plane, in the region opposite the beginning of the supply line. In the proposed antenna, the current is also concentrated at the edges of the patch and the power line. However on the ground plane, there is a concentration of current at the edges of the present lines.

A prototype of the proposed antenna was built and the images are shown in Fig. 11 and 12.

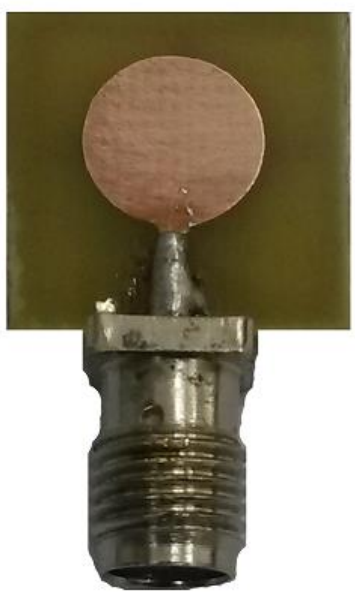

Fig. 11. Front view of the antenna built. 


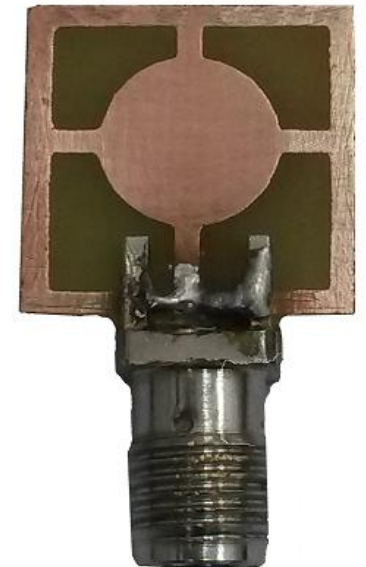

Fig. 12. Back view of the antenna built.

The return loss measurements were performed and the measured and simulated data were compared. This comparison is shown in Fig. 13.

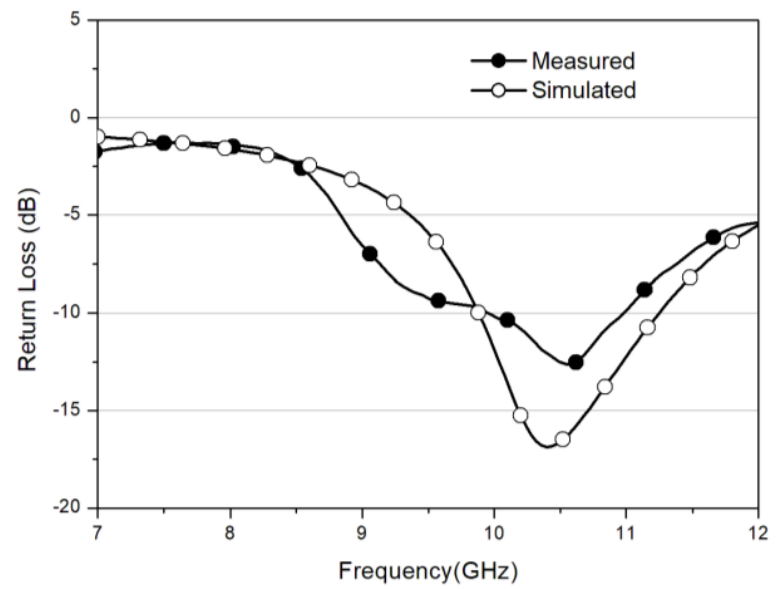

Fig. 13. Simulated and measured return loss for the proposed antenna.

The measured data show a small difference from the simulated data. However, a good approximation can be seen.

\section{Conclusions}

In this work a microfiche antenna was proposed and its properties were analyzed using computer simulations. When considering a land plane as a central circle connected by lines to the rectangular border, an improvement in bandwidth is achieved. While the standard antenna has a bandwidth of 643 $\mathrm{MHz}$, the proposed antenna has a bandwidth of
$1430 \mathrm{MHz}$, showing an increase of $122 \%$. Radiation diagrams and current distribution were also analyzed. The antenna prototype was built and the measured data were compared with the simulated ones showing good agreement.

\section{References}

[1] IEEE Transactions on Antennas and Propagation, vols. AP-17, no. 3, May 1969; AP-22, No. 1, January 1974; and AP-31, No. 6, Part II, November 1983.

[2] W. Y. Qiang and F. Tao, "The Study on a Patch Antenna with PBG Structure", Third International Symposium on Intelligent Information Technology Application (2009).

[3] C. A. Balanis, [Antenna Theory], WileyInterscience, New Jersey (2005), 146-149.

Y. M. Pan, S.Y. Zheng and B.J. Hu, "Wideband and Low-Profile Omnidirectional Circularly Polarized Patch Antenna", IEEE Trans. Antennas Propag, vol.62, no.8, (2014), 4347-4351.

[4] M. P. Sousa Neto, H. C. C. Fernandes and C. G. Moura. Design of a Ultrawideband Monopole Antenna Using Split Ring Resonator for Notching Frequencies. Mivrowave and Optical Technology Letters, vol. 56, (2014), 1471- 1473.

[5] O. P. Lavor, C. G. de Moura, H.C.C. Fernandes and M. P. Sousa Neto, "Analysis of a UWB Planar Antenna with Split Ring Resonator", Journal of Communications and Information Systems, vol. 30, no.1, (2015), 30-34.

[6] G. V. R. Xavier, E. G. da Costa, A. J. R. Serres and C. C. R. Albuquerque, "Metamaterial Application in a Circular Microstrip Antenna Developed for the Detection of Partial Discharges", 2019 IEEE International Symposium on Antennas and Propagation and USNC-URSI Radio Science Meeting, Atlanta, GA, USA, 2019, pp. 1965-1966.

[7] G. S. Shravan, L. Sai Suhas, N. G. Hemanth Kumar, S. Vinay and N. G. Girish Kumar, " 2 x2 
Circular Patch Antenna Array at 2.4 GHz for WSN Applications: Design and Performance Analysis of Circular Antenna Array and Comparison over Rectangular Array", 2019 International Conference on Communication and Electronics Systems (ICCES), Coimbatore, India, 2019, pp. 887-891.

[8] R. A. Panda, D. Mishra, P. Kumari, B. Hansdah and R. K. Singh, "Gauging trowel shaped patch with circular rings for $60 \mathrm{GHz}$ WLAN," 2020 7th International Conference on Signal Processing and Integrated Networks (SPIN), Noida, India, 2020, pp. 113-116.

[9] S. Samanta, P. S. Reddy and K. Mandal, "Cross-Polarization Suppression in Probe-Fed Circular Patch Antenna Using Two Circular Clusters of Shorting Pins", in IEEE Transactions on Antennas and Propagation, vol. 66, no. 6, pp. 31773182, June 2018.

[10] A. Ghosh and S. Das, Circular Patch Based Defected Ground RIS for Miniaturization and Bandwidth Improvement of Patch Antenna, 2018 International Conference on Computing, Power and Communication Technologies (GUCON), Greater Noida, Uttar Pradesh, India, 2018, pp. 412-415.

\section{Creative Commons Attribution License 4.0 (Attribution 4.0 International, CC BY 4.0)}

This article is published under the terms of the Creative Commons Attribution License 4.0

https://creativecommons.org/licenses/by/4.0/deed.en_US 